\section{DENTISTS BEST IN BRITAIN AT HANDLING CUSTOMER PHONE CALLS}

Dental surgeries are the best businesses in Britain when it comes to their phone manner, new research has revealed.

The study of 1,000 consumers, conducted on behalf of PH Media Group, discovered 53\% of Brits are satisfied with the way dentists' handle their calls, better than any other industry.

They are closely followed by the hotel trade, which boasts a 50\% satisfaction level, while printers performed the worst of all industries included in the survey, achieving just 18\% satisfaction.

'These results clearly reflect well on the dental profession and show surgeries are doing a good job of handling customer phone calls in a professional and efficient manner,' said Mark Williamson, Sales and Marketing Director, PH Media Group.

\section{NHS ENGLAND APPOINTS DEPUTY CHIEF DENTAL OFFICERS}

NHS England has appointed Janet Clarke and Eric Rooney (right) as Deputy Chief Dental Officers. They will both work part-time reporting to Sara Hurley, Chief Dental Officer.

As senior members of the Medical Directorate, they will work in partnership with other directorates, domain leads and other clinical leaders in regional and local area teams to improve outcomes for patients, and support the role of dentists and dentistry across the health system.

Janet is currently Associate Director for Dental Services in Birmingham Community Healthcare Trust and will start her new role on 1 January 2016. Her career has included the domains of wider healthcare policy, dental commissioning and undertaking operational healthcare management and strategic leadership assignments.

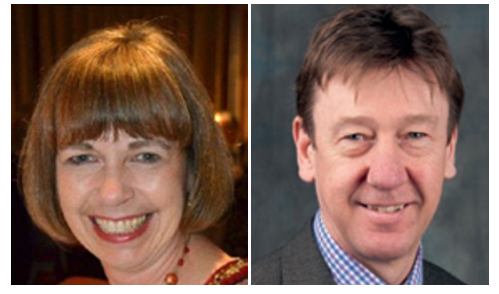

Janet said: 'I look forward to joining NHS England and working to further develop initiatives to continue to improve the oral health of adults and children, particularly the most vulnerable in our society.'

Eric, who joined NHS England in November from PHE, where he is a Consultant in Dental Public Health in the North West, said: 'I am excited about this opportunity to work with NHS England and the dental profession to develop and transform our dental services for the benefit of patients and the public.'

\title{
PLATFORM ANNOUNCES RECOMMENDATIONS FOR EU-WIDE ACTION ON ORAL HEALTH
}

The Platform for Better Oral Health in Europe has put forward its recommendations for improving oral health across all Member States.

Presented at the Second European Oral Health Summit in Brussels, Platform representatives discussed ways to reduce the economic and social burden of poor oral health in Europe, and the impact of oral diseases on quality of life.

Presenting the conclusions and recommendations, the Platform believes that:

- Cost effective oral health prevention and promotion can pay big dividends

- All Member states should work together and collaborate on promoting oral health

- Oral health needs to be mainstreamed in all European and national policies

- There is need to establish a Europe-wide framework for a common risk factor approach.

The collection contains 28 examples of good practices on oral health prevention and promotion programmes from across Europe, which the Platform sees as possible solutions for reducing the burden of oral diseases and oral health inequalities both within and between Member States.

Dr Paula Vassallo, Chair of the Platform for Better Oral Health in Europe, said: 'We need to devise a plan for joint action on oral health, or put in place a mechanism for sharing best practices between Member States.

'If we can establish a European wide framework for common risk factor management, in line with a European communication strategy, I firmly believe we can make great strides in tackling totally preventable dental disease.

'We are not calling on Member States to reinvent the wheel. However we urge them to take on these examples of best practice, adapt them where necessary to their country and add value. Strategies have and are working elsewhere, so use them.' 